\title{
Temporary external flow mechanical circulatory support: Going with the flow?
}

\author{
Claude Beaty, MD, and Ming-Sing Si, MD \\ From the Department of Cardiac Surgery, Section of Pediatric Cardiovascular Surgery, University of Michigan, \\ Ann Arbor, Mich. \\ Disclosures: Authors have nothing to disclose with regard to commercial support. \\ Received for publication March 19, 2018; accepted for publication March 21, 2018; available ahead of print April \\ $18,2018$. \\ Address for reprints: Ming-Sing Si, MD, 11-735 C.S. Mott Children's Hospital SPC 4204, 1540 E Hospital Drive, \\ Ann Arbor, MI 48109-4204 (E-mail: mingsing@umich.edu). \\ J Thorac Cardiovasc Surg 2018;156:166-7 \\ $0022-5223 / \$ 36.00$ \\ Copyright $(2) 2018$ by The American Association for Thoracic Surgery \\ https://doi.org/10.1016/j.jtcvs.2018.03.075
}

Treatment of patients with acute cardiogenic shock includes venoarterial extracorporeal life support (VA-ECLS) via peripheral cannulation or placement of a left ventricular assist device (LVAD). The latter option can be further specified as placement of a temporary extracorporeal LVAD or a longterm implantable LVAD as a bridge to recovery or heart transplantation. In this issue of the Journal, Ando and colleagues ${ }^{1}$ present their 10-year single-center experience with this set of patients and how their management using mechanical circulatory support has evolved. By comparing different time periods, the authors found that the use of these temporary LVADs over time has been associated with an increase in prior percutaneous mechanical circulatory support such as VA-ECLS, an increase in minimally invasive LVAD configurations, and a decrease in cohort mortality both in-hospital and at 1 year. However, no difference was found in the rates of various treatment outcomes, such as recovery, transplantation, or definitive LVAD therapy.

On the basis of their collective and evolving experience, VA-ECLS has become the authors' first-line rescue technique with temporary LVADs placed via a minimally invasive approach as a follow-up therapy. VA-ECLS has proven itself as a rapidly deployable rescue therapy and has even been instituted in the prehospital setting. ${ }^{2}$ However, although VA-ECLS can reestablish sufficient cardiac output, this strategy does have some shortcomings: the inability to decompress the failing and distended left ventricle while subjecting it to increased afterload, upper body hypoxemia, ${ }^{3}$ and the inability of these patients to ambulate. Placement of temporary LVADs and right ventricular assist devices via sternotomy increases the risk of durable LVAD placement or transplantation because of the dense adhesions. Therefore, these authors have adopted a minimally invasive approach to place a temporary $\mathrm{LVAD}^{4}$ that permits ambulation, decompresses the failing left ventricle, and decreases the amount of adhesions.

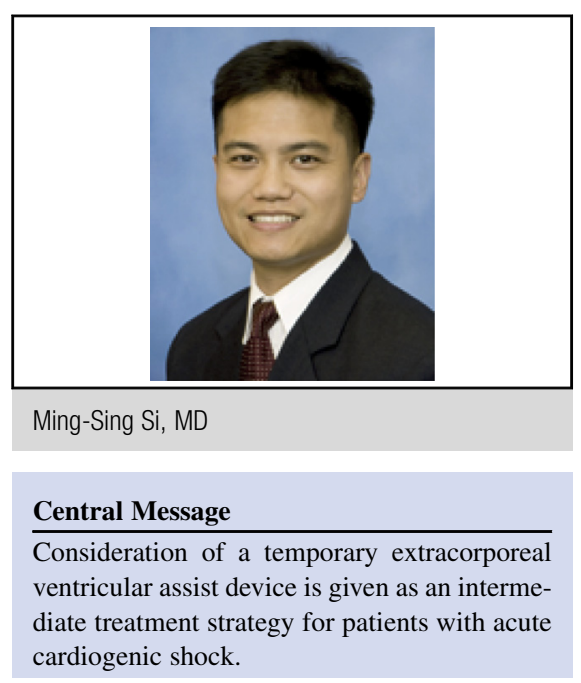

See Article page 157

One may argue that transitioning to a durable LVAD from VA-ECLS would eliminate the intermediate extracorporeal LVAD placement. However, these authors have shown in their experience that more than one third of their patients manifested enough recovery to wean off temporary LVAD support, whereas one quarter required transition to a durable LVAD. Therefore, going to a durable LVAD may be unnecessary in a considerable number of patients. On the other hand, one can also argue that placing a temporary LVAD was unnecessary in the $25 \%$ of patients who were eventually transitioned to a durable LVAD. This dilemma highlights a critical inability of predicting the probability of left ventricle recovery in patients with acute cardiogenic shock. By improving predictive performance in this area, possibly by the use of diverse techniques including imaging, biomarkers, ${ }^{4}$ and machine learning ${ }^{5}$ to determine the viability and probability of functional recovery, clinicians would be able to select the best type of mechanical circulatory support option for these patients initially, thereby avoiding multiple staged procedures. Alternatively, implementing a fully implantable LVAD that is minimally traumatic and does not require removal of ventricular muscle (to ensure the maximum probability of recovery) may eliminate the distinction between a temporary and durable LVAD. Until these improvements are made, the approach by Ando and colleagues ${ }^{1}$ warrants further consideration and adoption. 


\section{References}

1. Ando M, Garan AR, Takayama H, Topkara VK, Han J, Kurlansky P, et al. A continuous-flow external ventricular assist device for cardiogenic shock: evolution over 10 years. J Thorac Cardiovasc Surg. 2018;156: 157-65.e1.

2. Lamhaut L, Hutin A, Puymirat E, Jouan J, Raphalen JH, Jouffroy R, et al. A pre-hospital extracorporeal cardio pulmonary resuscitation (ECPR) strategy for treatment of refractory out hospital cardiac arrest: an observational study and propensity analysis. Resuscitation. 2017;117:109-17.

3. Rupprecht L, Lunz D, Philipp A, Lubnow M, Schmid C. Pitfalls in percutaneous ECMO cannulation. Heart Lung Vessel. 2015;7:320-6.

4. Shibata R, Numaguchi Y, Matsushita K, Sone T, Kubota R, Ohashi T, et al Usefulness of adiponectin to predict myocardial salvage following successful reperfusion in patients with acute myocardial infarction. Am J Cardiol. 2008; 101:1712-5.

5. Shameer K, Johnson KW, Glicksberg BS, Dudley JT, Sengupta PP. Machine learning in cardiovascular medicine: are we there yet? Heart. January 19, 2018 [Epub ahead of print]. 